\title{
Fast Processing of the Articles and User Friendly Websites: Significant Bases for the High Impact Factor of Journals in Open Access Publishers
}

\section{Zahra Mojtahedi*}

Institute for Cancer Research, Shiraz University of Medical Sciences, Shiraz, Iran

Article processing in scholar journals has several expenses including those of physical environment, secretary, website design and publications of the articles. For covering these expenses, scholarly peer-reviewed journals follow different strategies. In some of them, the readers have to pay. Other journals that freely release the full text of their articles are either supported by an institution or the authors are asked to pay a fee for article processing stages except the reviewer stage (http://www.biomedcentral.com/info/about/whtis). Obviously, reviewers should not have any financial relationship with authors which may seriously affect the review stage.

The primary aim of free access journals is free distribution of science all over the world wherever internet is reachable. Supposedly, a free access to articles provide the chance of more visibility of an article and subsequently more citations [1]; in truth, only authorpaid journals in an open access publisher have usually proved an increasing impact factor, the main indicator of higher quality articles, compared to other free access journal models supported just by an institution (http://admin-apps.webofknowledge.com/). What is the motivation in submitting high quality works to journals covered by an open access publisher? The main differences between the two models of free access journals are fast processing of articles and user-friendly websites of journals in open access publishers. From submission date to publication, it sometime takes more than 1 year in non-author paid free journals. One reason for the long time of article processing in such journals might be low financial supports that potentially affect article processing in different stages such as assigning a manuscript number and proof preparation. The time interval between submission date and publication or even rejection is too short in journals supported by open access publishers. In fact, this distinction as well as user friendly websites makes author-paid journals in open access publishers ideal for high quality works. A new international open access publisher is
OMICS publishing group (http://omicsonline.org) that covers about 100 journals on a variety of subjects. Its article processing period is too short, usually less than two months [2]. Particularly, interval between acceptance and publication is normally just a few days [3]. This publisher has created a very user friendly website. The other exclusive priority of OMICS website is the audio facility for articles, making an opportunity for non-native English people to hear the right pronunciation of the words. The unique aspects of OMICS publishing group can essentially assist to free and fast exchange of knowledge and play a significant role in scientific advancement of the world in near future.

Through providing fast processing and free access to full text of the articles and also user-friendly websites, open access publishers motivate the authors to submit their original works to the corresponding journals. It is suggested that non-open access journals trial transferring to an open access publisher. Also, authors may initially include the article processing fee in their research grants. Exceptional features of open access publishers have increased the impact factors of the related journals despite their short time of activity. No financial relationship between authors and reviewers is the basis for sustaining their high qualities.

\section{References}

1. Gargouri Y, Hajjem C, Larivière V, Gingras Y, Carr L, et al. (2010) Self-selected or mandated, open access increases citation impact for higher quality research. PLoS One 5: e13636.

2. Hamed RH, Elzahaf E (2011) Low Dose Weekly Paclitaxel Versus Low Dose Weekly Cisplatin with Concomitant Radiation in Locally Advanced Head and Neck Cancers. J Cancer Sci Ther 3: 166-171.

3. Razmkhah MRazmkhah M, Jaberipour M, Ghaderi A (2011) Chemokines and Chemokine Receptors Expression in the Adipose Derived Stem Cells (ASCs) Breast Tissues and in Peripheral Blood of Patients with Breast Cancer. J Carcinogene Mutagene 2: 120-126.
*Corresponding author: Zahra Mojtahedi MD, PhD, Assistant Professor of Immunology, Shiraz Institute for Cancer Research, Shiraz University of Medical Sciences, Shiraz, Iran, Tel: +98 711230 3687; Fax: +98 711230 3687; E-mail: mojtahedizahra@hotmail.com

Received February 14, 2012; Accepted February 18, 2012; Published February 20, 2012

Citation: Mojtahedi Z (2012) Fast Processing of the Articles and User Friendly Websites: Significant Bases for the High Impact Factor of Journals in Open Access Publishers. Metabolomics 2:e111. doi:10.4172/2153-0769.1000e111

Copyright: (C) 2012 Mojtahedi Z. This is an open-access article distributed unde the terms of the Creative Commons Attribution License, which permits unrestricted use, distribution, and reproduction in any medium, provided the original author and source are credited. 